\title{
Structural Chemistry author wins Nobel Prize
}

\author{
Istvan Hargittai ${ }^{1}$
}

Published online: 27 October 2016

(C) Springer Science+Business Media New York 2016

\begin{abstract}
The 2016 Nobel Prize in Chemistry highlighted another spectacular achievement in structural chemistry and supramolecular chemistry. The three awardees built molecular machines based on their intimate knowledge of molecular properties and behavior. One of the three laureates, J. Fraser Stoddart, with two co-authors, published an invited paper in 1999 in our journal in which they surveyed the interplay between the synthesis of functioning supramolecular systems and their X-ray crystallographic investigation. Structural Chemistry congratulates Stoddart and his co-laureates on this momentous occasion.
\end{abstract}

Keywords J. Fraser Stoddart · Nobel Prize · Molecular machines $\cdot$ Supramolecular chemistry

Lately, it has been a rare occasion when the Nobel Prize in Chemistry would go for discoveries that could be considered purely in chemistry. This is not surprising because chemistry has been in the forefront of milestone discoveries in the biomedical sciences. Nonetheless, it is heartwarming when the Stockholm judges find purely chemical discoveries also worthy of this most prestigious recognition. The Nobel Prize in Chemistry 2016 was awarded jointly to the French Jean-Pierre Sauvage (1944), the British-born American J. Fraser Stoddart (1942) and the Dutch Bernard L. Feringa (1951) for designing and synthesizing molecular machines.

Istvan Hargittai

istvan.hargittai@gmail.com

1 Department of Inorganic and Analytical Chemistry, Budapest University of Technology and Economics, PO Box 91, 1521 Budapest, Hungary
Some of what J. Fraser Stoddart (Fig. 1) received his share of the Nobel Prize for was already there in the overview titled "X-ray Crystallographic Studies on the Noncovalent Syntheses of Supramolecules" by Matthew C. T. Fyfe, J. Fraser Stoddart, and David J. Williams in 1999 [1]. It was published in a special collection of Structural Chemistry, Volume 10, Issue 3, arranged by two guest editors, Simon G. Bott of the University of Houston and Alan P. Marchand of the University of North Texas. Already then, the importance of Stoddart's work received recognition and one of the Figures of the overview made it to the cover of Structural Chemistry (Fig. 2). Stoddart at that time was affiliated with the Department of Chemistry and Biochemistry, University of California at Los Angeles; now, he is with the Department of Chemistry, Northwestern University, in Evanston, Illinois.

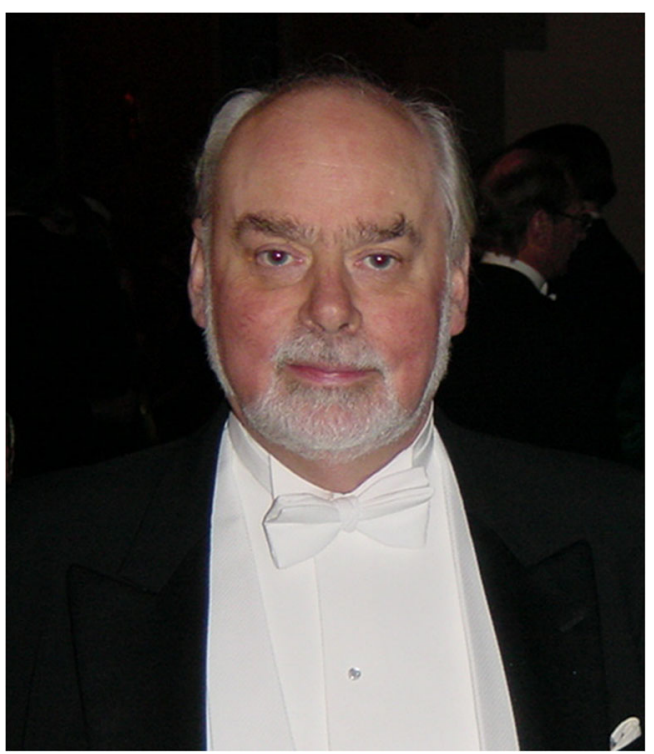

Fig. 1 J. Fraser Stoddart in 2001 in Stockholm during the centenary celebrations of the Nobel Prize (photograph by I. Hargittai) 
Fig. 2 Cover of Structural Chemistry, Volume 10, Issue 3; the art is Figure 27 from "X-ray Crystallographic Studies on the Noncovalent Syntheses of

Supramolecules" by Matthew C.

T. Fyfe, J. Fraser Stoddart, and

David J. Williams (pp 243-259)
ISSN 1040-0400

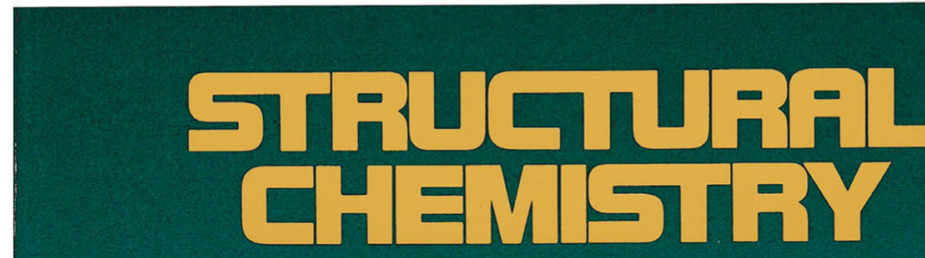

Computational and Experimental Studies of Chemical and Biological Systems

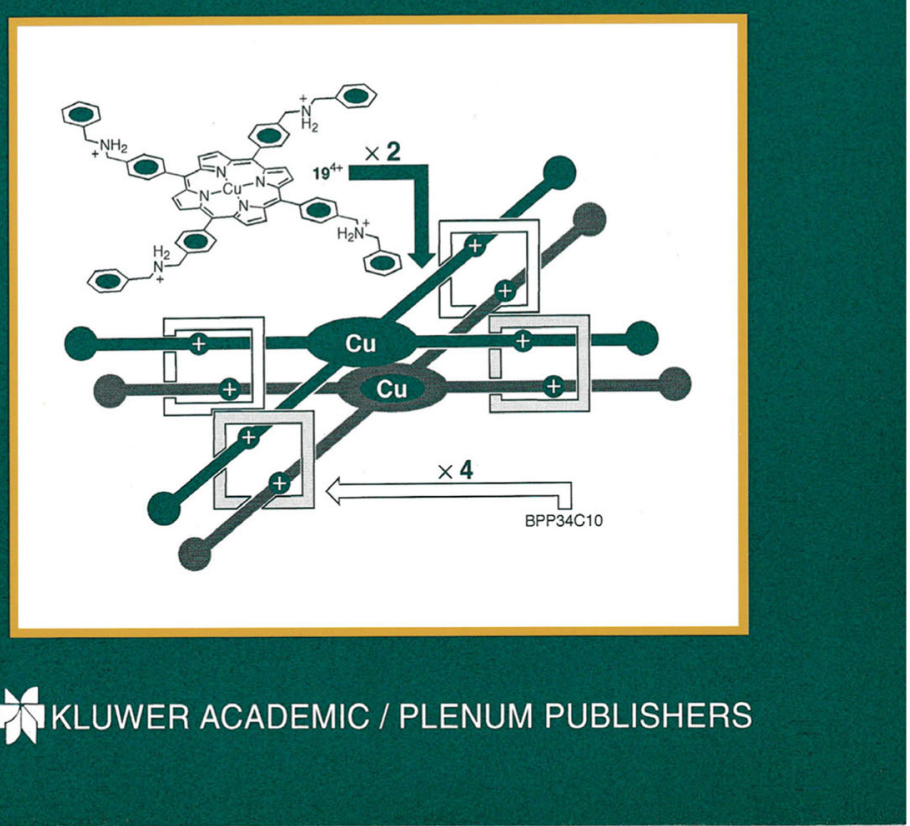

The photograph displayed here was taken during the centenary celebrations in Stockholm, on December 10, 2001. We bumped into each other at the banquet in the Stockholm City Hall, following the award ceremony in the Stockholm Concert Hall. It was a great privilege to attend these events, especially in this centennial year as guests of the Royal Swedish Academy of Sciences. Fifteen years later, on December 10, 2016, Stoddart is once again in Stockholm, in a different capacity; not as a spectator, but one receiving the prize. Our congratulations to him and his co-laureates!

\section{References}

1. Fyfe MCT, Stoddart JF, Williams DJ (1999) Struct Chem 10:243259 